\title{
Pulse Neutron Subcritical KEFF Measurements on Water Flooded Arrays of Fuel Rods
}
B. M. Durst
S. R. Bierman
E. D. Clayton

July 1980

Prepared for the U.S. Department of Energy under Contract DE-AC06-76RLO 1830

Pacific Northwest Laboratory Operated for the U.S. Department of Energy by Battelle Memorial Institute 
NOTICE

This report was prepared as an account of work sponsored by the United States Government. Neither the United States nor the Department of Energy, nor any of their employees, nor any of their contractors, subcontractors, or their employees, makes any warranty, express or implied, or assumes any legal liability or responsibility for the accuracy. completeness or usefulness of any information, apparatus, product or process disclosed, or represents that its use would not infringe privately owned rights.

The views, opinions and conclusions contained in this report are those of the contractor and do not necessarily represent those of the United States Government or the United States Department of Energy.

PACIFIC NORTHWEST LABORATORY

operated by

BATTELLE

for the

UNITED STATES DEPARTMENT OF ENERGY

Under Contract DE-AC06-76RLO 1830

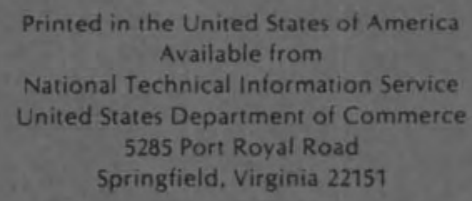

Price: Printed Copy $\mathbf{S}$ $\therefore$ Microfiche $\$ 3.00$

NTIS

- Pages Selling Price

001-025 $\$ 4.00$

026-050 $\quad 54.50$

051-075 $\$ 5.25$

076-100 $\quad \$ 6.00$

$107-125 \quad \$ 6.50$

$126-150 \quad \$ 7.25$

$151-175 \quad \$ 8.00$

$176-200 \quad 59.00$

201-225 $\$ 9.25$

226-250 $\$ 9.50$

$251-275 \quad \$ 10.75$

276-300 $\$ 11.00$ 


\section{5}

PULSE NEUTRON SUBCRITICAL KEFF MEASUREMENTS ON WATER FLOODED ARRAYS OF FUEL RODS

B. M. Durst

S. R. Bierman

E. D. Clayton

July 1980

Prepared for the U.S. Department of Energy under Contract DE-AC06-76RLO 1830

Pacific Northwest Laboratory

Richland, Washington 99352 
CONTENTS

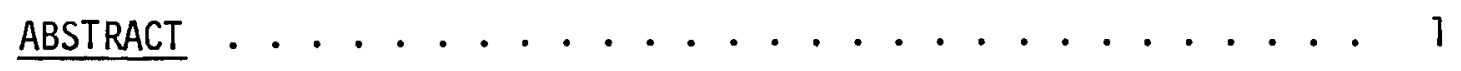

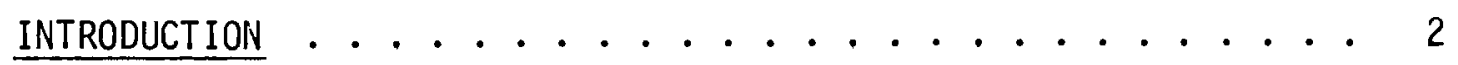

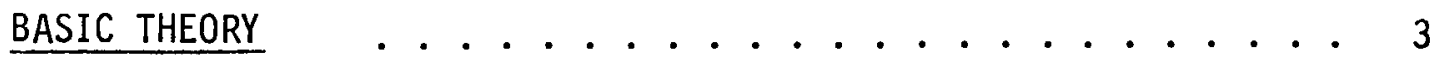

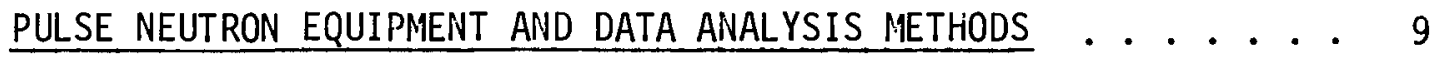

PULSE NEUTRON MEASUREMENTS PERFORMED AT BATTELLE ON . . . . . . . 14 WATER MODERATED ARRAYS OF FUEL RODS

Pulsed Neutron Measurements on a Neutron Multiplier Lattice • 14

Pulse Neutron Measurements with Unirradiated Clusters of . . 20 Low Enriched Uranium Dioxide Rods

Measurements with Irradiated Pu-Al Fuel Elements in . . . . 26 A Shipping Cask Insert

Subcritical Measurements on Mark-1A Fuel Elements in . . . 29 the Hanford $\mathrm{N}$-Reactor Storage Basin

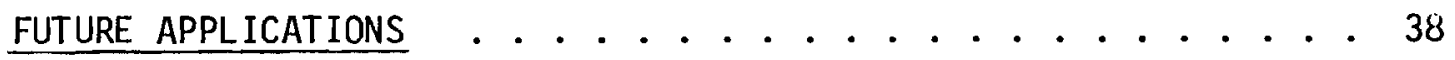

CONCLUSIONS . . . . . . . . . . . . . . . . . . . . 41

REFERENCES . . . . . . . . . . . . . . . . . 42 


\section{LIST OF FIGURES}

Figure 1 Raw Data from an Ideal Pulsed Neutron Source . . 4 Measurement

Figure 2 Pulsed Neutron Source anci Data Acquisition .... 10 System

Figure 3 Kaman Nuclear Model A808 Pulsed Neutron Source . . 11

Figure 4 Example of Actual Data from a Pulsed Neutron. . . . 13 Measurement

Figure 5 Neutron Multiplier Assembly - Showing Highly ... 15 Enriched U-Al Rods and 2 Inch Void Tube in Array Center

Figure 6 Fuel Rods Used in Neutron Multiplier . . . . . 16

Figure 7 Pulsed Neutron Source Measurement Results - . . 18 Neutron Multiplier Lattice

Figure $8 \quad K_{\text {eff }}$ from Pulsed Neutron Source Measurements - . . 21 Neutron Multiplier Lattice

Figure 9 Description of Low Enriched $\mathrm{UO}_{2}$ Fuel Element. . . 22

Figure 10 Pulsed Neutron Measurements of Three Cluster . . . 23 Experiments

Figure 11 Prompt Neutron Decay Rates and System Reactivity. . 25 as a Function of Fuel Cluster Separation 
Figure 12 Description of Sol id Cylindrical Pu-Al Element . . . 27

Figure 13 Experimental Arrangement for Pulsed Neutron . . . 28 Measurements of Loaded Insert

Figure 14 Pulsed Neutron Heasurenents Performed on . . . . . 32 Irradiated Uranium in the $\mathrm{N}$-Reactor Fuel Basin

Figure 15 Top View of Experimental Assembly ....... 33 


\section{LIST OF TABLES}

TABLE I Unirradiated Mark-1A Fuel Element ....... 30 Dimensions and Isotopic Composition

TABLE II Experimental Data on 3.2-inch Pitched ..... 35 Hexagonal Lattice of Unirradiated Mark-1A

Fuel in water

TABLE III Experimental Data on 3.2-inch Pitched ..... 36 Hexagonal Lattice of Irradiated Mark-1A

Fuel in Water 
. 


\section{$\underline{\text { ABSTRACT }}$}

The pulsed neutron source technique has been utilized at the Pacific Northwest Laboratory for some twenty years for measurement of subcritical reactivities of a variety of fuel systems. One area of application has included measurements of subcritical reactivities of water flooded arrays of fuel rods. This report sumnarizes these measurements. The theory behind the measurement process is reviewed and the instrumentation of the measurement system discussed. Also, four experiment programs are described in detail, illustrating system use and flexibility. Some changes are suggested for system improvements to speed up data collection and data reduction, and some possible areas of future application of the method are described. 


\section{INTRODUCTION}

The pulsed neutron source technique has been used for nearly twenty years at the Pacific Northwest Laboratory in measuring subcritical reactivities of a variety of fuel systems. It has been used to measure the worth of poison materials, measure changes in reactivity brought about by system parameter changes such as from an increase in mass or concentration. One particular area where it has been substantially applied is in the measurement of reactivity of water flooded arrays of fuel rods.

This paper will concentrate on these experiments, illustrating the pulsed neutron method's use and flexibility. All of the experiments which will be described were performed to collect data against which calculational techniques could be checked. Much of the data was acquired in the near critical region $\left(k_{\text {eff }}>0.9\right)$. However, some measurements were made on systems with $k_{\text {eff }} \sim 0.6$. Some fuel arrays measured were "green" unirradiated fuel while some were "spent" fuel and highly radioactive. The intent of this report is to demonstrate the applicability of the pulsed neutron method for measurement of subcritical reactivities of fuel rod configurations in water, and also to suggest ways in which the system might be improved and utilized in future applications. 


\section{BASIC THEORY}

In the pulsed neutron source measurements, a burst of neutrons is injected into a system in a fraction of a microsecond and its effect on the neutron population at some point in the system is observed as a function of time following the burst. In actual practice, the measurements are made by repetitively injecting bursts of neutrons into the system and accumulating the observed time behavior following each burst. The repetition rate and number of neutron bursts required depends on the statistics of the accumulated data, which, in turn, is dependent on the particular system. A proportional counter, $\mathrm{BF}_{3}$ tube, or a fission counter is generally used for the detection of the neutrons, and a multi-channel analyzer is used as a series of sequentially gated scalers for the storage of the neutron counts as a function of time following each burst.

To determine the degree of subcriticality of a system, the raw data obtained from a pulsed neutron source measurement should, ideally, look something like that shown in Figure 1. Each data point shown represents the total number of neutrons counted during a time interval positioned at that point in time between the neutron bursts. Since the neutron detector generally used is primarily sensitive to thermal neutrons, the count rate may be seen to increase immediately following the neutron burst. As the fast neutrons slow down and become thermalized, the count rate will reach a maximum and then beginto decrease exponentially. Once an asymptotic distribution of neutrons is reached in the system, 


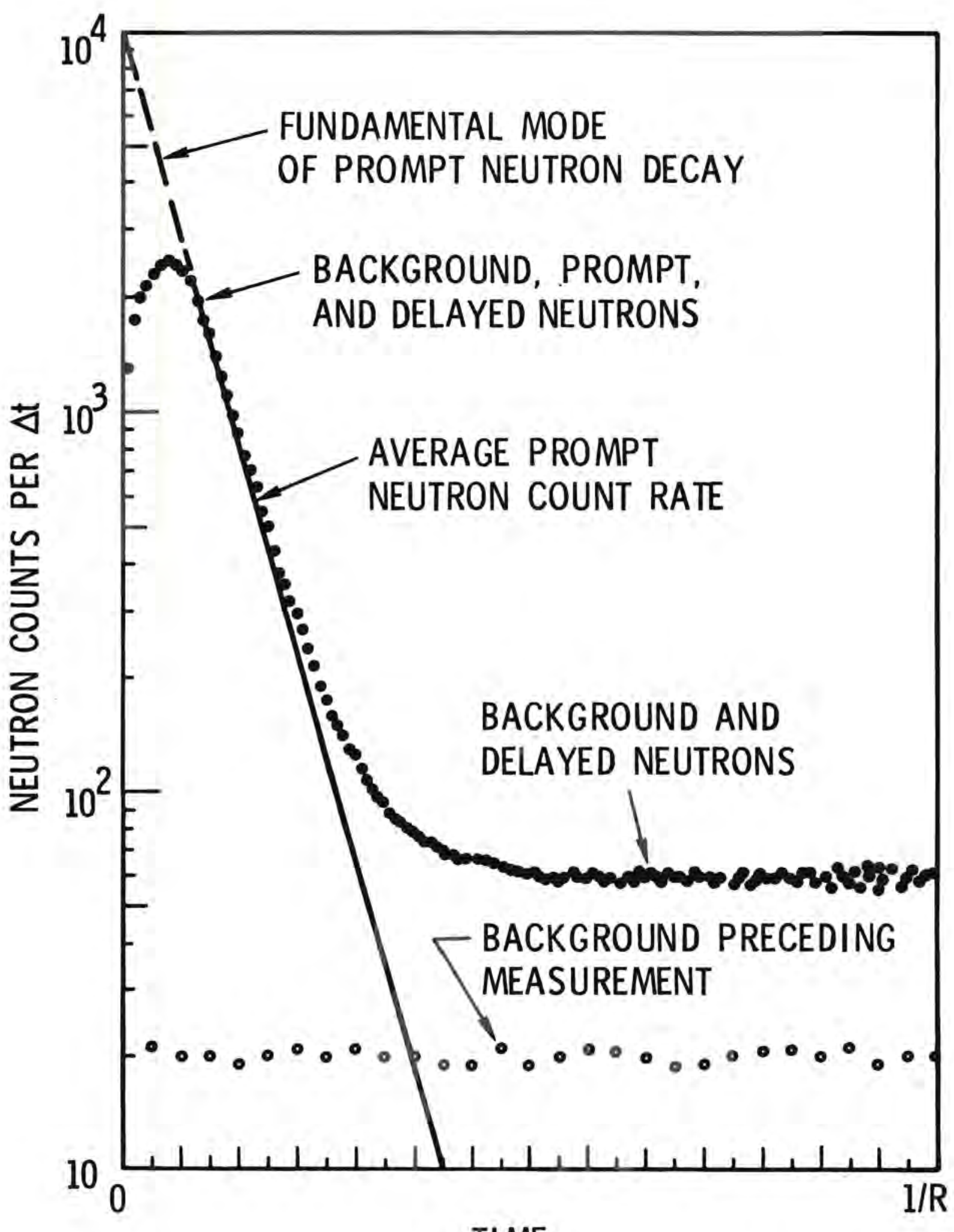

TIME

Figure 1. Raw Data from an Ideal Pulse Neutron Source Heasurerient 
the count rate, as a function of time following the neutron burst, can be described as the sum of two exponential terms:

$$
n(t)=A e^{-\alpha 1}+A_{2} e^{-\alpha_{2} t}
$$

One term describes the time behavior of the prompt neutrons and the other describes the time behavior of the delayed neutrons. Since the decay of the delayed neutrons is very slow compared to that of the prompt neutrons, Equation 1 is written as:

$$
n(t)-A_{1} e^{-\alpha_{1} t}+N_{D}
$$

where $N_{D}$ is a constant equal to the averaged delay neutron contribution and

$$
A_{1} e^{-a_{1} t}
$$

is the prompt neutron contribution.

After a period of time, the prompt neutron portion of the total population that is due to the neutron burst will approach the background level preceding the burst, and only the delayed neutrons will remain. Since the prompt neutrons must all decay away before the delayed neutron contribution can be determined, the prompt neutron decay rate is a limiting factor in determining the pulse repetition rates and counting time intervals to be used. This rate of decay is dependent upon the 
system on which the measurements are being made. However, the faster the neutron spectrum is, the faster will the decay rate be. Also, the further subcritical a system is, the faster the decay rate will be. It is this ambiguous feature of the prompt neutron decay which prevents it being used as a direct measurement of reactivity, although it is directly related to the reactivity of the given system. The rate of decay of the prompt neutrons can, however, be used to obtain an effective multiplication constant, $k_{e f f}$, for the system by the following relationship:

$$
a_{0}=\frac{1-k_{e f f}\left(1-\beta_{e f f}\right)}{\ell},
$$

where $\alpha_{0}$ is the decay rate $-\alpha_{1}$, $\beta_{\text {eff }}$ the effective delayed neutron fraction, and $\ell$ the neutron lifetime in the system. However, this requires a knowledge of $\ell$ and $\beta_{\text {eff }}$ and $\ell$ is as difficult to calculate as $k_{\text {eff }}$.

Equation 3 and the definition for reactivity,

$$
\rho \equiv \frac{k-1}{k}
$$

can be combined to obtain an expression for the reactivity of system in units of $\beta-$ i.e. dollars. 


$$
\frac{\rho}{\beta}=-\frac{\alpha_{0}-k \beta / \ell}{k \beta / \ell}
$$

If the neutron generation time is assumed to be constant, then Equation 5 reduces to:

$$
\frac{\rho}{\beta}=-\frac{{ }^{\alpha}{ }_{0}-{ }^{\alpha} c}{\alpha_{c}}
$$

where $a_{c}$ is the prompt neutron decay rate at delayed critical $(k=1)$. However, the generation time does vary significantly with the degree of subcriticality. Also, $\alpha_{c}$ is a parameter not generally available for plant systems.

Three methods have been developed whereby the reactivity of a system can be determined directly from raw data such as that shown in Figure 1. All three methods are similar in that, in each case, the reactivity of the system is related to the areas under the curve generated by the pulsed neutron source measurement. The earliest technique was suggested by sjostrand ${ }^{(1)}$ who simply separated the data into a prompt neutron component and a delayed neutron component, as implied by Equations 1 and 2, and then approximated the reactivity by taking the ratio of the area under the prompt neutron curve to the area under the delayed neutron curve,

$$
\left(\frac{\rho}{\beta}\right)_{S J}=-\frac{\text { Prompt Neutron Area }}{\text { Delayed Neutron Area }}
$$


Gozani ${ }^{(2)}$ improved on this by extrapolating the prompt neutron fundamental mode of decay back to time zero following the burst of neutrons, and taking the reactivity as:

$$
\left(\frac{\rho}{\beta}\right)_{G O}=-\frac{\text { Prompt Neutron Fundamental Mode Area }}{\text { Delayed Neutron Area }}
$$

Garelis and Russel1 ${ }^{(3)}$ developed a more rigorous theoretical model and showed that the prompt neutron count rates multiplied by a factor involving the reactivity of the system must equal the total area under the pulsed neutron source curve between time zero and $1 / R$ following the burst of neutrons.

$$
\int_{0}^{l / R} N_{p} e^{\frac{k \beta}{\ell} t} d t=\int_{0}^{1 / R} N_{p} d t+\frac{N_{D}}{R}
$$

Where, $N_{p}$ is the prompt neutron count rate at time $t$ following the burst, $N_{D}$ is the averaged delayed neutron count rate, and $R$ is the pulse repetition rate.

All the information needed to solve Equation 9 for $k \beta / \ell$ is available in the data obtained from the pulsed neutron source measurement. Consequently, all the data needed to solve Equation 5 for the reactivity of the system is provided by the pulsed neutron source data in the GarelisRussell model. No other information is needed about the system. 


\section{PULSE NEUTRON EQUIPMENT AND DATA ANALYSIS METHODS}

The pulsed neutron source measuring system is shown in Figure 2. The heart to the system is a Kaman Nuclear Model A808 pulsed neutron source having a relatively high neutron yield of $\sim 10^{9} \mathrm{n} / \mathrm{sec}$. (See Figure 3). Deuterons are accelerated within the source tube striking a target containing tritium, thus generating $14 \mathrm{MeV}$ neutrons from the well known D, T reaction. The accelerating voltage can be pulsed to provide pulses of neutrons at rates ranging up to abut 50 pulses per second. The source is encased in a six-inch diameter cylinder, 36 inches long that can easily be moved about. This latter feature is of primary importance in applying the pulsed neutron source technique in the field. Output from the analyzer is stored on paper tape for subsequent transfer to punched cards and, finally, input into a computer code for data reduction. A Canberra Model 8100 multichannel analyzer stores the neutron population as a function of time.

The code PNSLEARN, an adaptation, by D. A. Kottwitz, G. D. Seybold, and Pamela Skorpik of the computer code LEARN $(4,5)$ is utilized in the data reduction, least-squares fitting, and analysis of the pulsed neutron source data. Briefly, the computer program corrects the raw pulse neutron data for coincidence losses, converts it to a time base (seconds), leastsquare fits a pre-selected time interval of the data to

$$
Y=A_{1}+\sum_{j=2}^{j j} A_{j} e^{\left[-A_{j+1} X\right]}, A_{3}>A_{5},
$$




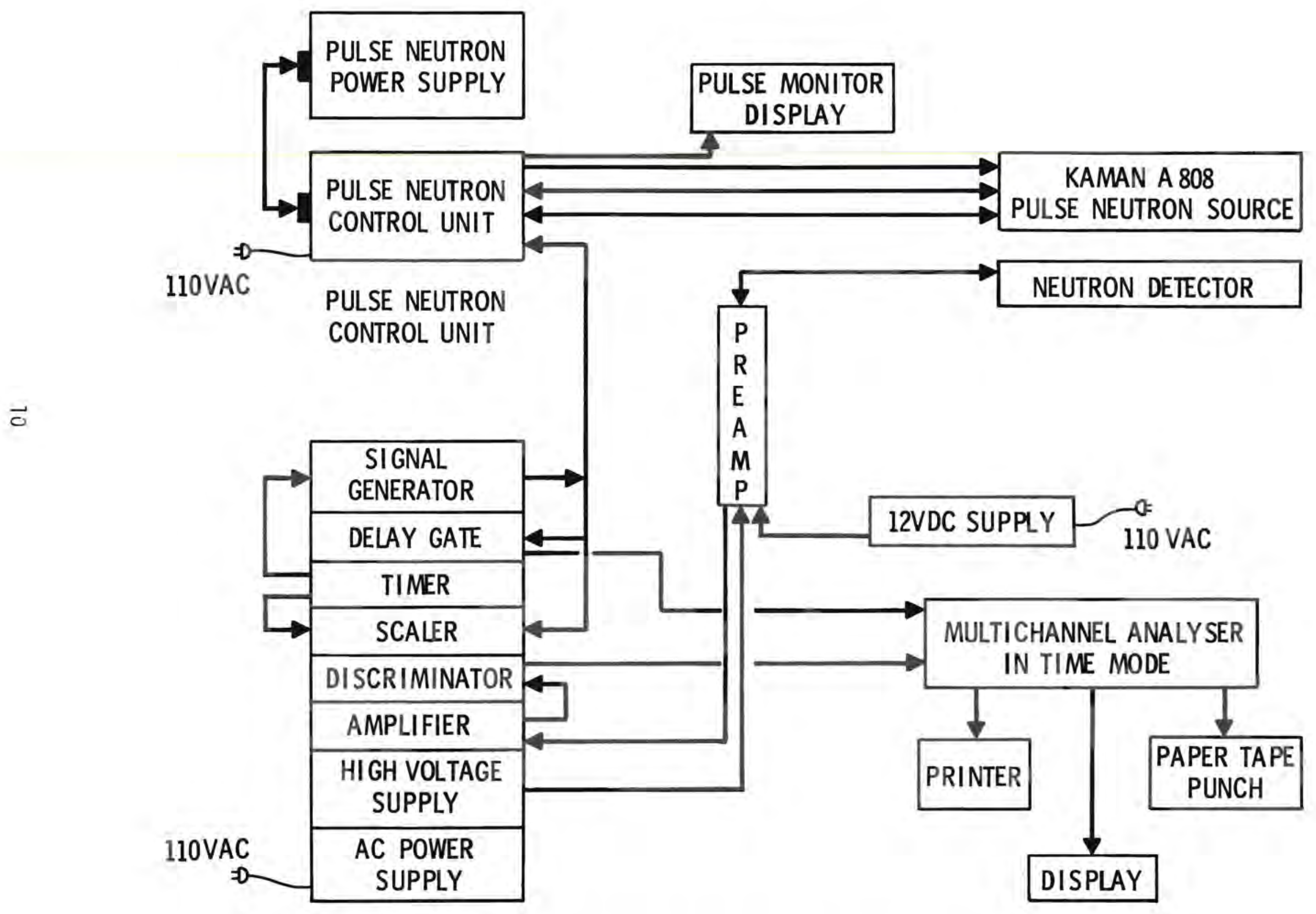

Figure 2. Pulse Neutron Source and Data Acquisition System 


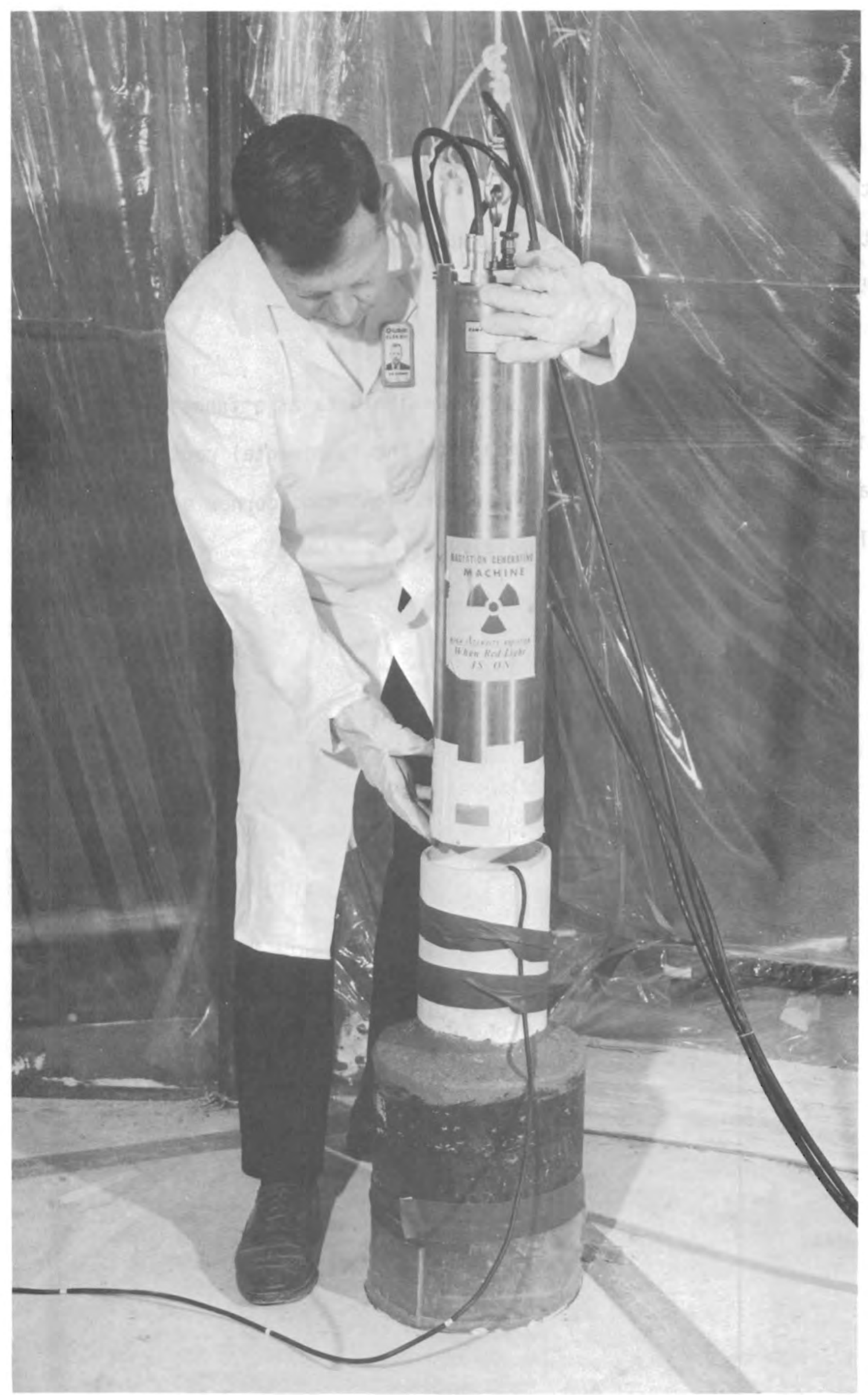

Figure 3. Kaman Nuclear llodel A808 Pulsed Neutron Source 
and then performs reactivity analyses of the data by both the Gozani and the Garelis-Russell techniques. These techniques are used as they tend to bracket the "true" $k_{\text {eff }}{ }^{(6)}$ The $k_{\text {eff }}$ determined by averaging the Gozani and Garel is-Russell values together, is then taken to be the "true" $k_{\text {eff }}$ of the system.

The code plots the neutron population data as a function of time for the desired fit and summarizes the fundamental neutron parameters for the system in the upper right hand corner of the plot (see Figure 4 for an example). 


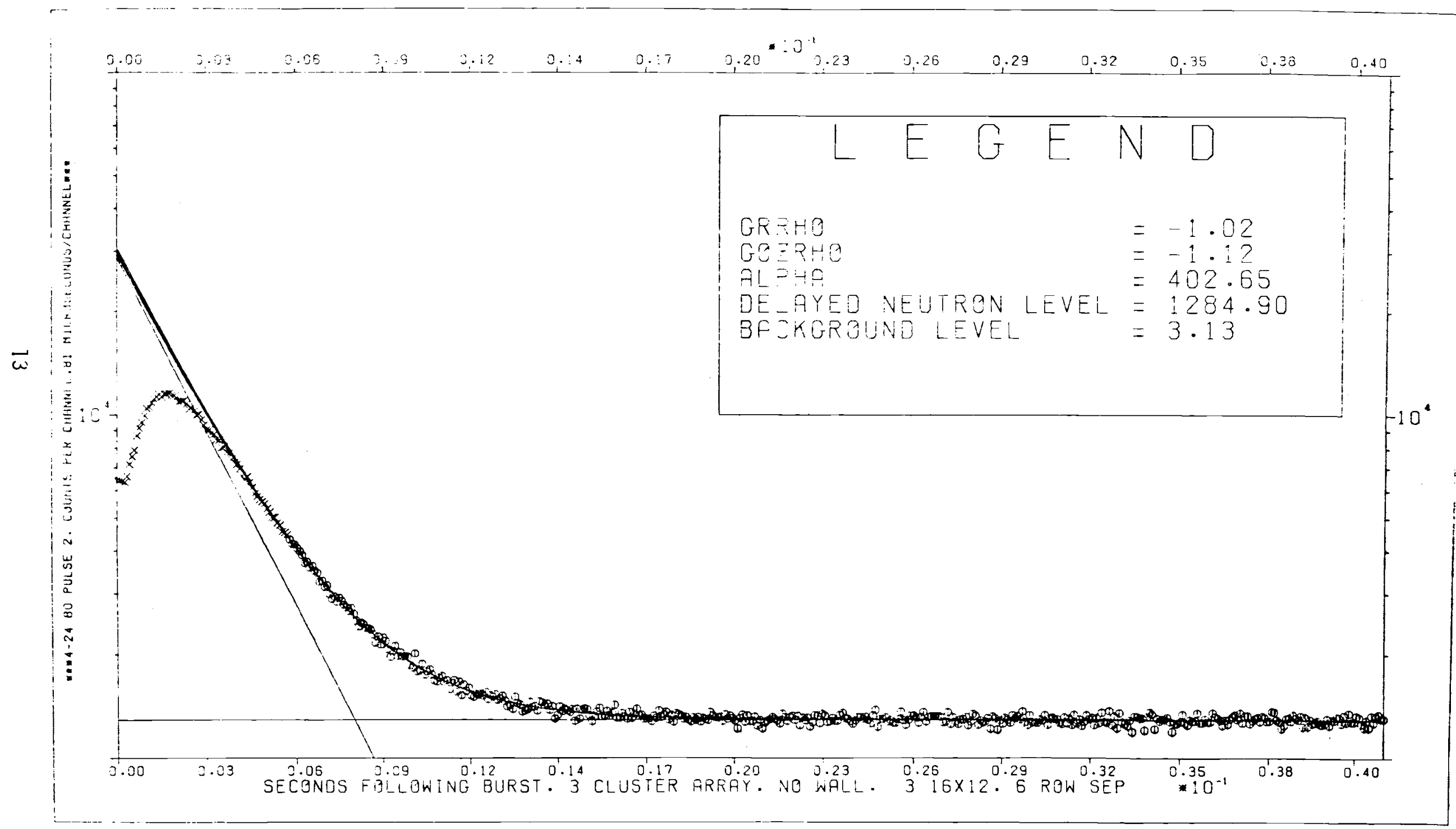

Figure 4. Example of Actual Data from a Pulse ileutron lieasurement 
Pulsed neutron source measurements on subcritical assemblies include: (1) a neutron multiplier lattice, filled with highly enriched uranium rods, (2) unirradiated clusters of low enriched uranium dioxide rods, (3) irradiated PuAl fuel elements in a shipping cask insert, and (4) measurements on irradiated and unirradiated Mark-1A low enriched uranium fuel elements in a reactor storage basin. The multiplication constant or $k_{\text {eff }}$ for these assemblies ranged between 0.6 and near unity with both unirradiated and irradiated fuel being used.

\section{Pulsed Neutron Measurements on a Neutron Multiplier Lattice}

The experimental system consisted of an annular lattice assembly, reflected and moderated with water, contained in a cylindrical tank having a diameter of $102 \mathrm{~cm} .{ }^{(7)}$ Measurements were made at lattice spacings of 0.55 and 0.60 inch. A photograph of the assembly is shown in Figure 5. The canned fuel rods were composed of a $U+A 1$ alloy having a ${ }^{235} U$ enrichment of $93.2 \mathrm{wt} \%$; they were 0.40 inch in diameter and $23-3 / 4$ inches in length. Detailed dimensions are shown in Figure 6 .

The lattices were safely loaded, using the critical approach method; this also provided the extrapolation for the critical number of rods. At 


\section{NEUTRON MULTIPLIER LATTICE}

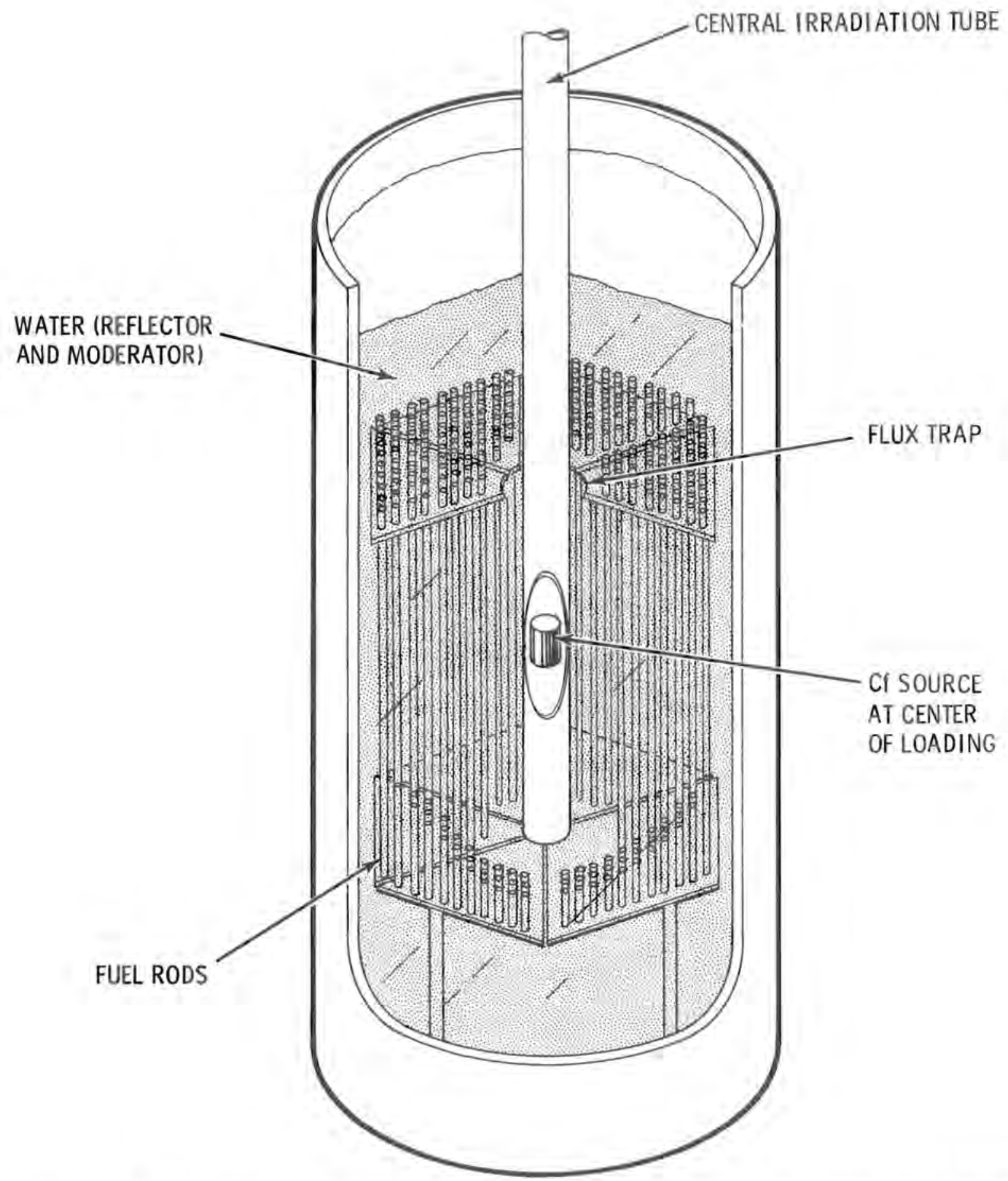

Figure 5. Neutron Multiplier AssembTy - Showing Highly Enriched U-A1 Rods and 2 Inch Void Tube in Array Center 


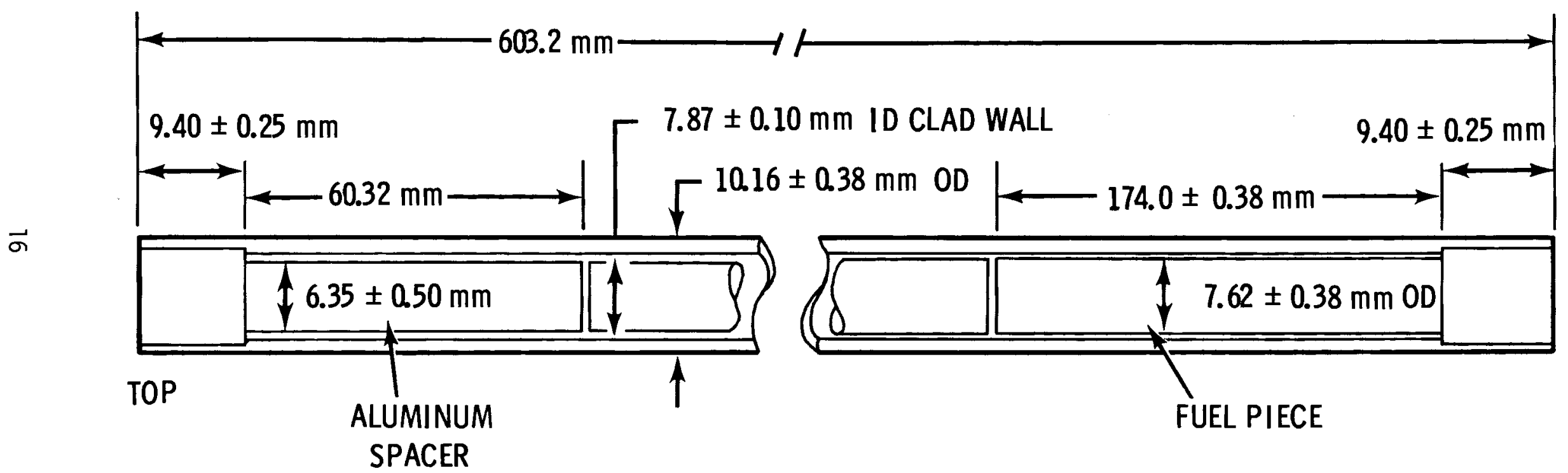

CLAD MATERIAL: ALUMINUM, 1100

LOAD MATERIAL: $28 \mathrm{w} / 0 \mathrm{U}$ IN AI, $93.2 \mathrm{w} / \mathrm{o}^{235} \mathrm{U} \mathrm{IN} \mathrm{U}, 1 \mathrm{gm} \mathrm{U}(93.2) / \mathrm{cm}^{3}$. 3 FUEL PIECES PER ROD. $22.224 \mathrm{gm}^{235} \mathrm{U}$ PER ROD 
selected fuel loadings, pulsed neutron source measurements were made to determine the prompt neutron decay rate and the reactivity.

Pulsed neutron source measurements were performed on the lattice assembly having a 0.6-inch spacing. The measurements were conducted at room temperature $\left(\sim 21^{\circ} \mathrm{C}\right)$ and with a 2 -inch void tube running axially through the center of the flux trap. The pulsed neutron source was positioned in the reflector region away from the fuel rods with its tritium target approximately at the mid-plane of the lattice. Two neutron detectors were used, independently, for data accumulation. The primary detector, a $\mathrm{BF}_{3}$ tube, was located at the center of the lattice in the 2-inch void tube to minimize spatial effects in the data. However, as the delayed critical condition was approached, a secondary neutron detector (a boron-line proportional counter), located in the reflector region opposite the pulsed neutron source, could be, and was, relied upon for data accumulation.

Measurement data were obtained on five symmetrical fuel rod loadings nearest the delayed critical loading as predicted by the companion critical approach measurements. Each set of data was least-squares fit to a single exponential term plus a constant to determine the prompt neutron decay rate for each fuel loading. The data were analyzed using both the Garel is-Russell method and the Gozani method to determine the reactivity of each fuel loading. The results of these data analyses are shown graphically in Figure 7. Experimentally determined corrections of about $0.5 \%$ in mass were applied to all the measurement results to account 


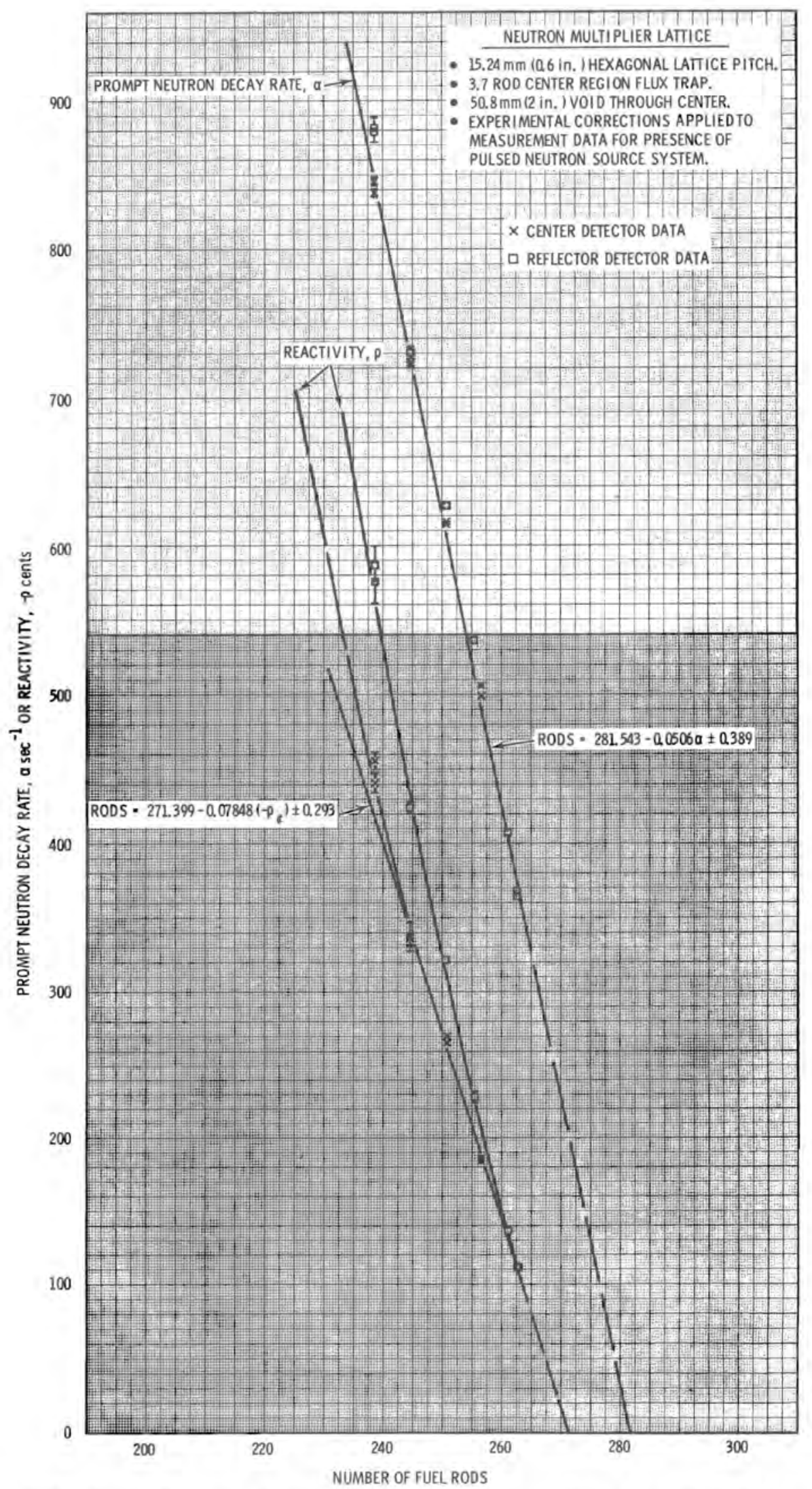

Figure 7. Pulsed Neutron Source Measurement Results - Neutron Hiltiplier Lattice 
for the presence of the pulsed neutron source system. The number of fuel rods required for criticality was 271.4 without the pulsed neutron system and 272.9 with it in position.

Data from both detectors yielded decay rates which varied linearly over the fuel loading range, with no apparent dependency on the data source. By linearly extrapolating these subcritical data to the prompt critical condition, a prompt critical loading of 281.5 fuel rods is obtained.

Not unexpectedly, some spatial effects were observed in the reactivity analyses of these measurement data. As shown in Figure 7, analyses of the data accumulated with the detector located in the reflector region gives different reactivity values from those obtained from the data accumulated with the detector loacted in the center of the fuel lattice. However, as the delayed critical condition is approached, the reactivity values converge such that the data obtained from the detector in the reflector gives the same value for the reactivity of the largest subcritical fuel loading as does an extrapolation of the data from the center detector. By extrapolating these subcritical data to the delayed critical condition, a delayed critical loading of 271.4 fuel rods is obtained.

Effective neutron multiplication constants $\left(k_{\text {eff }}\right)$ have been determined from the reactivity data shown in Figure 7 by assuming a value of 0.0065 
for $\beta_{\text {eff }}$. These $k_{\text {eff }}$ values as a function of fuel rod loading are shown in Figure 8. A curve is also shown in Figure 8 depicting the reactivity effect resulting from filling the lower half of the center void tube with water. In all instances, $k_{\text {eff }}$ was $\geq 0.9$.

\section{Pulsed Neutron Measurements with Unirradiated Clusters of Low Enriched} Uranium Dioxide Rods

One common method employed in storing spent fuel is to separate clusters of fuel rods by different thicknesses of water. The system reactivity due to cluster interaction, hence, is greater than for a single flooded cluster of fuel.

Pulsed neutron source measurements were performed on unirradiated water flooded clusters of $4.3 \mathrm{wt} \%{ }^{235} \mathrm{U}$ enriched $\mathrm{UO}_{2}$ fuel rods. The fuel elements analyzed are described in Figure 9. The rods were arranged into three $12 \times 16$ rectangular clusters of fuel rods constructed on a $18.9 \mathrm{~mm}$ pitch and separated by varying amount of water. (See Figure 10).

The center fuel array's position was held fixed while the outer two arrays were progressivley moved in closer to the center in order to approach the delayed critical condition. At the different water gap separations between the fuel clusters, pulsed neutron measurements were performed to determine reactivity changes with water gap variation. 


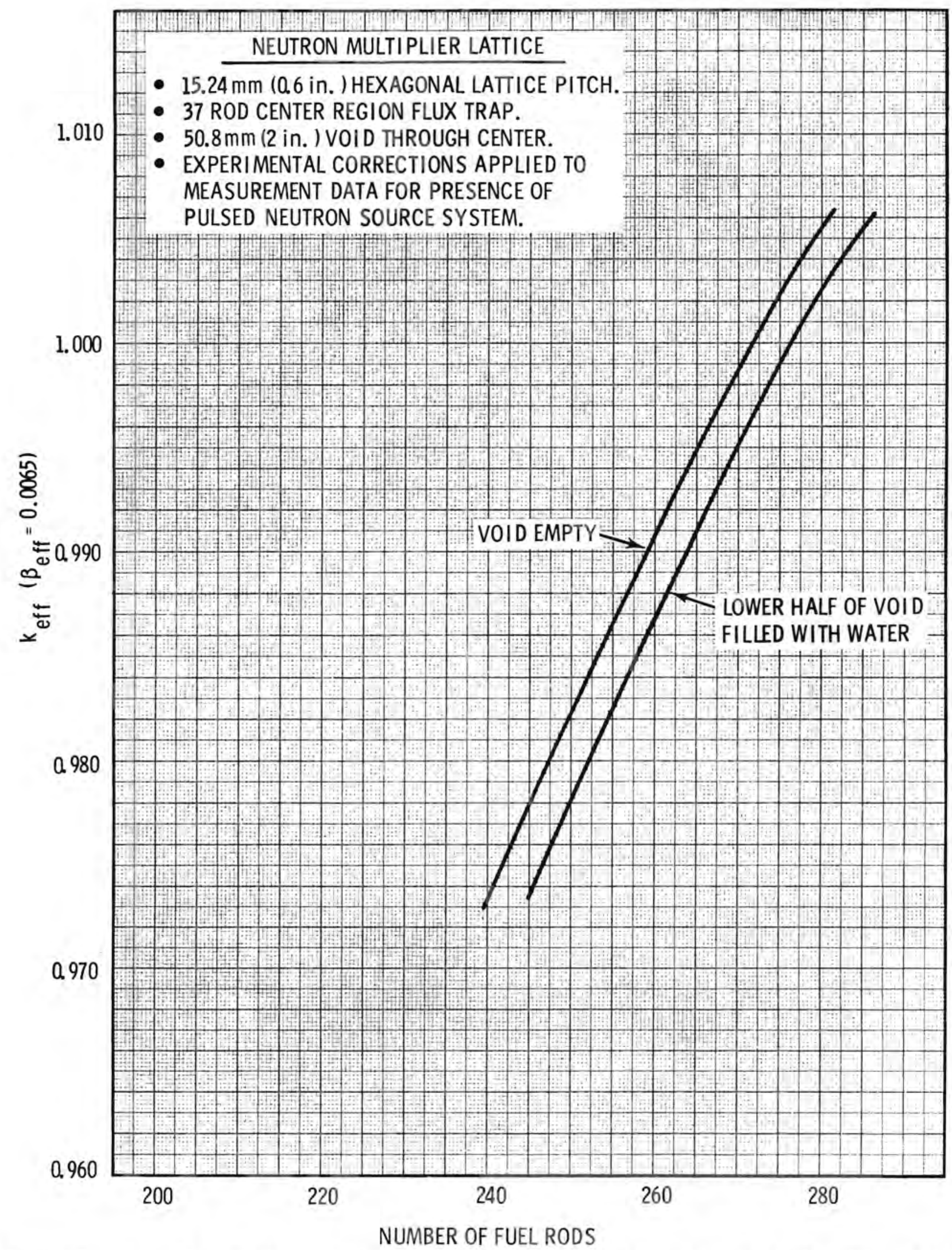

Figure 8. K $K_{\text {eff }}$ from Pulsed Neutron Source Measurements - Neutron Multiplier Lattice 


\section{$4.31 w t \%^{235}$ U ENRICHED UO 2 RODS}

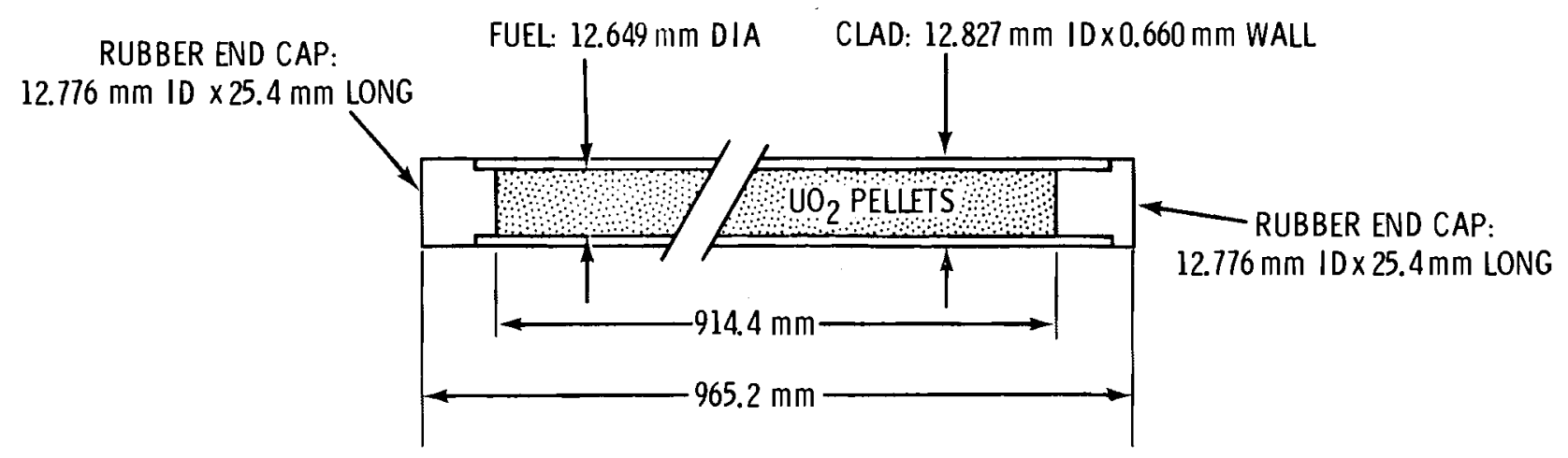

CLADDING: 6061 ALUMINUM TUBING

LOADING:

ENRICHMENT $-4.31 \pm 0.01 \mathrm{wt} \%{ }^{235} \mathrm{U}$

FUEL DENSITY $-94.9 \pm 0.55 \%$ OF THEORETICAL DENS ITY

URANIUM ASSAY $-88.055 \pm 0.261 \mathrm{wt} \%$ OF TOTAL FUEL COMPOSITION

$\mathrm{UO}_{2}-1203.38 \pm 4.12 \mathrm{~g} / \mathrm{ROD}$

END CAP:

DENSITY $-1.321 \mathrm{~g} / \mathrm{cm}^{3}$

COMPOSITION-C $-58 \pm 1 w t \% \quad S-1.7 \pm 0.2 w t \%$

$H-6.5 \pm 0.3 w t \% \quad 0-22.1 w t \%$ (BALANCE)

$\mathrm{Ca}-11.4 \pm 1.8 w t \% \quad$ Si $-0.3 \pm 0.1 w t \%$

Figure 9. Description of Low-Enriched $\mathrm{UO}_{2}$ Fuel Elements 
I)

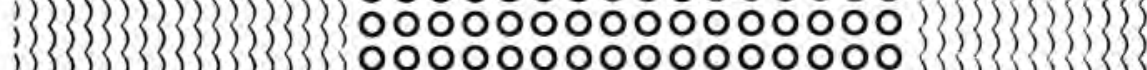
0000000000000000

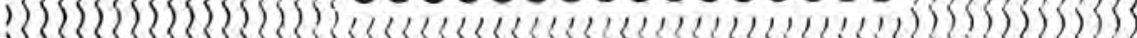

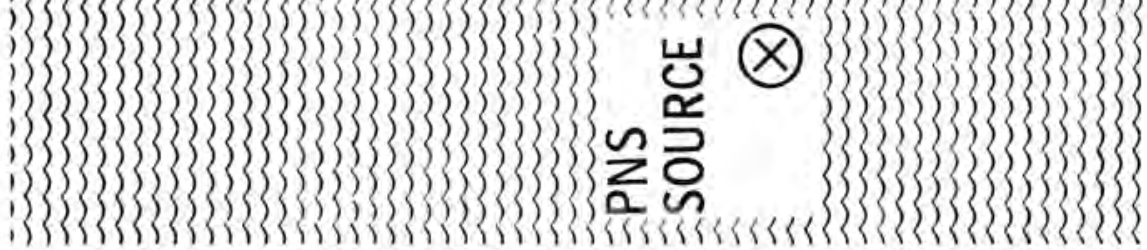


The pulsed neutron source was placed at one end of the array while the detector was placed near the array center in the reflector region. Data from the experiment (See Figure 11) shows how both the prompt neutron decay rate and reactivity vary with water separation between fuel clusters. The predicted critical water separation between fuel clusters of $12.9 \mathrm{~cm}$ agreed well with that result predicted by the critical approach method. The prompt condition was predicted to occur at a water separation of 11.6 $\mathrm{cm}$. At a separation of $\sim 13.7 \mathrm{~cm}$ (final loading) the value of $\mathrm{k}_{\text {eff }}$ for the interacting array was measured to be 0.996 . 


\section{PROMPT NEUTRON DECAY RATES AND SYSTEM REACTIVITY AS A FUNCTION OF FUEL CLUSTER SEPARATION}

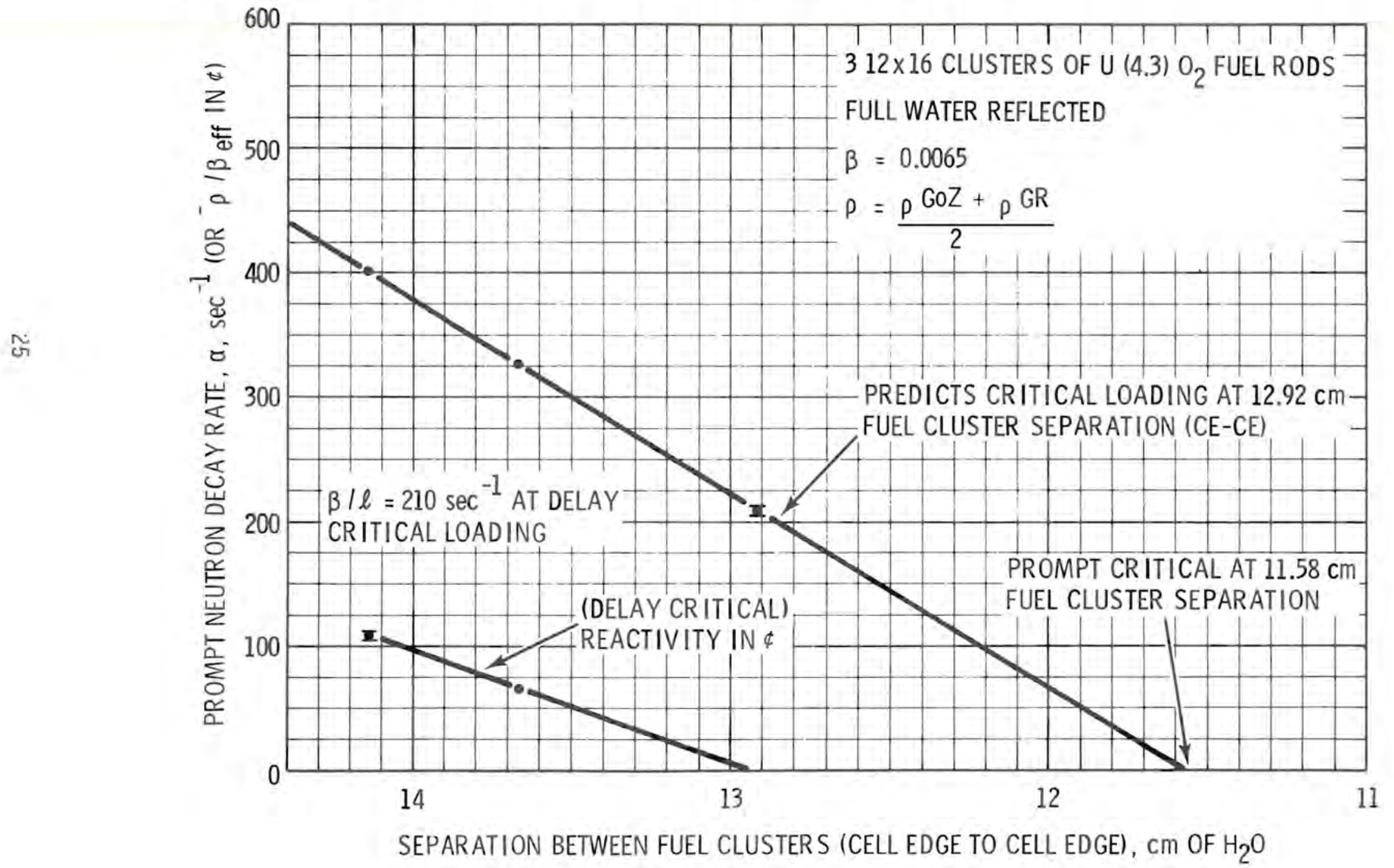

Figure 11. Prompt Neutron Decay Rates and System Reactivity as a function of Fuel Cluster Separation 
Measurements with Irradiated Pu-Al Fuel Elements in A Shipping Cask Insert

Experiments were performed on irradiated Pu-Al fuel elements prior to loading in a shipping container. ${ }^{(8)}$ Calculations had shown that if critical mass values were used for unirradiated fuel elements then criticality considerations would have required more than six fuel shipments.

The experiments yielded data on the reactivity of these fuel elements that could be used to establish criticality safety of the shipment on the basis of the larger critical mass values for the irradiated fuel as opposed to the unirradiated fuel.

The fuel element description is given in Figure 12. The pulsed neutron source measurement geometry is shown in Figure 13. On one side of the shipping cask insert was placed the Kaman A808 pulser head. On the other side was placed a lead shielded $\mathrm{BF}_{3}$ neutron detector. The measurements indicated that $k_{e f f}$ was $\simeq 0.77$ and hence, the assembly was highly subcritical. (This was a single measurement experiment; no approach to critical was performed). These elements had undergone an exposure of $\sim 25000 \mathrm{MWD} /$ ton of fuel and were highly radioactive. Measurements were performed remotely under ten feet of water, in a reactor fuel storage basin at Hanford, Washington. As a result of these measurements, the actual transport under exposed fuel criticality control limits required only two cask shipments, instead of six. 


$\begin{array}{ll}\text { Aluminum Clad OD, cm } & 3.78 \\ \text { Core (PuAl) OD, cm } & 3.29 \\ \text { PuAl Core Density, } \mathrm{g} / \mathrm{cm}^{3} & 2.88 \\ \text { Aluminum Density, } \mathrm{g} / \mathrm{cm}^{3} & 2.7 \\ \text { Core Cimposition w/o Pu in Al } & 6.0 \\ \text { Pu Isotopic Composition, w/o Isotope in Pu } & 75 \mathrm{w} / \mathrm{o} \mathrm{Pu}-239,20 \mathrm{w} / \mathrm{O} \mathrm{Pu}-240 \\ & 4 \mathrm{w} / 0 \mathrm{Pu}-241,1 \mathrm{w} / \mathrm{O} \mathrm{Pu}-242\end{array}$

Figure 12. Description of Solid Cylindrical Pu-Al Element 


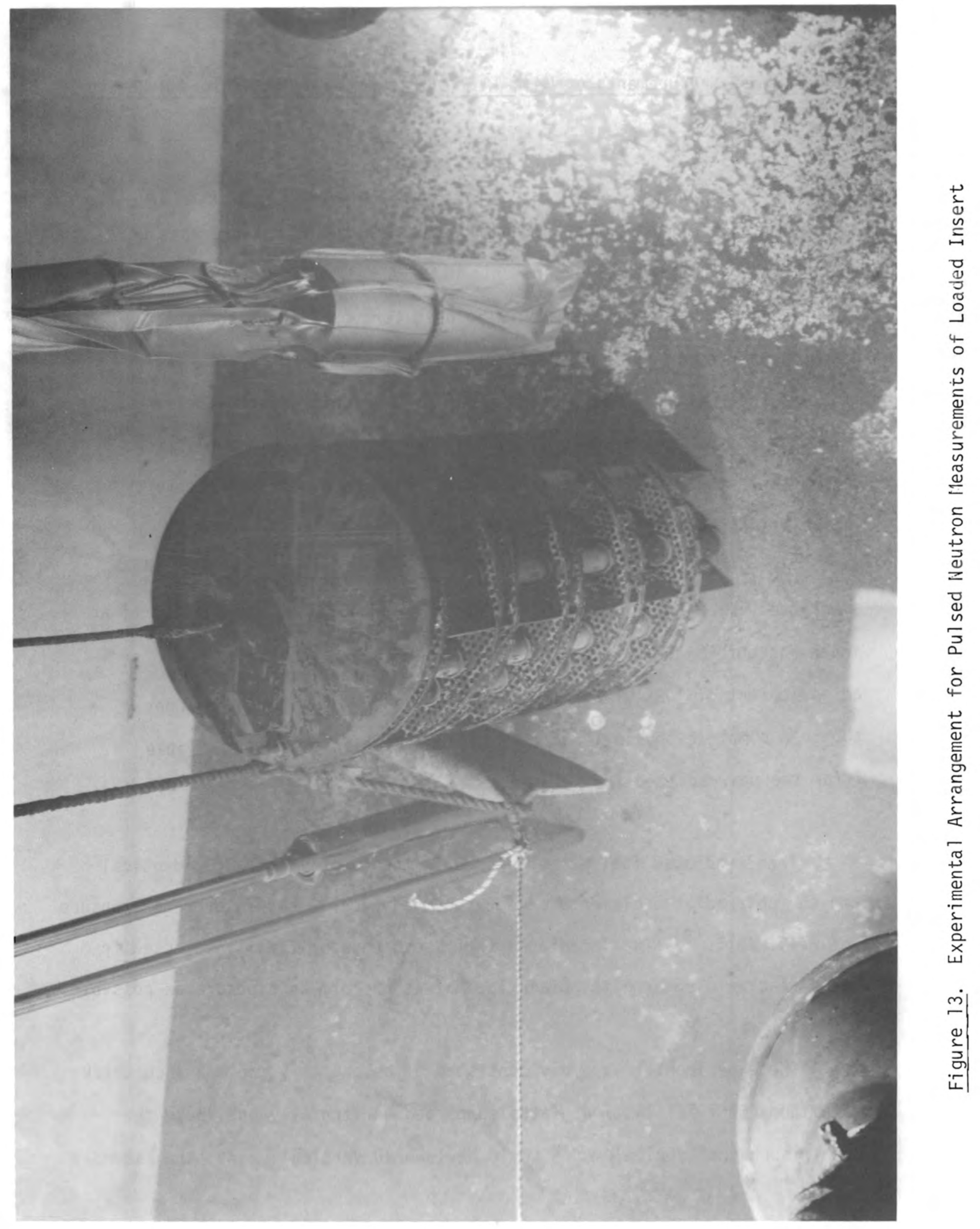


Subcritical Measurements on Mark-1A Fuel Elements in the Hanford N-Reactor Storage Basin

Pulsed neutron source and neutron multiplication measurements were performed in a series of experiments with MARK-1A uranium fuel elements in water to obtain data that could be used for verifying calculational techniques used in setting criticality safety limits for spent reactor fuel storage arrays. Measurements were made on unirradiated fuel elements and on fuel elements that had been subjected to known uniform exposure in the $\mathrm{N}$-Reactor to permit obtaining the necessary reactivity correlations between green and spent fuel.

The MARK-1A fuel elements are about 21 -inches long and consist of an inner and outer tube of uranium clad in zirconium. The uranium has an enrichment of $1.25 \mathrm{wt} \%$ in the outer tube and $0.95 \mathrm{wt} \%$ in the inner tube. A complete physical and chemical description is given in Table I for the unirradiated fuel elements.

The irradiated fuel elements used in the experiments were identical to the unirradiated elements except they had experienced an average exposure of $2740 \mathrm{MWD} / \mathrm{T}$. (9) The irradiated fuel had been specifically selected from an $\mathrm{N}$-Reactor discharge to obtain fuel of as uniform an exposure as possible.

The experimental assembly consisted of essentially two 1/2-inch thick aluminum (6061-T6) lattice plates supported horizontally one above the other such that fuel elements could be lowered vertically into the assembly 
Outer Tube

$\begin{array}{lrl}\text { Zirconium Clad OD in. (cm) } & 2.404(6.106) \\ \text { Uranium OD in. (cm) } & 2.354(5.979) \\ \text { Uranium ID in. (cm) } & 1.817(4.615) \\ \text { Zirconium Clad ID in. (cm) } & 1.767(4.488) \\ \text { Clad Fuel Length in. (cm) } & 20.88 \text { (53.04) } \\ \text { Uranium Core Length in. (cm) } & 20.51 \quad(52.10) \\ \text { Weight of Element U 1b. (kg) } & 24.45 \text { (11.09) } \\ \text { Uranium Composition w/o U-235 } & 1.25 \\ \text { w/o U-238 } & 98.70 \\ \text { w/o U-234 } & 0.01 \\ \text { w/o U-236 } & 0.04\end{array}$

Inner Tube

Zirconium Clad OD in. (cm) $1.246(3.165)$

Uranium OD in. $(\mathrm{cm}) \quad 1.666(2.962)$

Uranium ID in. (cm) $0.490(1.245)$

Zirconium Clad ID in. $(\mathrm{cm}) \quad 0.440(1.118)$

$\mathrm{Cl}$ ad Fuel Length in. (cm) $20.82 \quad$ (52.88)

Uranium Core Length in. (cm) $20.45 \quad$ (51.94)

Weight of Element $U$ 1b. $(\mathrm{kg}) \quad 12.21 \quad$ (5.538)

Uranium Composition w/o U-235 0.947

W/O U-238 $\quad 99.00$

W/O U-234 0.01

$\mathrm{W} / 0 \mathrm{U}-236 \quad 0.04$

Assembly Weight U 1b. (kg)

$36.7(16.6)$

Density Uranium $18.9 \mathrm{~g} / \mathrm{cc}$

Density Zirconium $6.4 \mathrm{~g} / \mathrm{cc}$ 
in a hexagonal pattern having a fixed lattice spacing of 3.2 inches. (Calculations had indicated that a lattice spacing of 3.2 inches was near optimum, with respect to critical mass, for both the unirradiated and the irradiated fuel elements). ${ }^{(8)}$ The lattice plates were approximately four feet apart. A photograph of the experimental assembly, in position, on the floor of the $\mathrm{N}$-Reactor Storage Basin, is shown in Figure 14.

Fuel elements were positioned in the lattice by loading two fuel elements, one above the other, in a $3^{\prime \prime}$ O.D. aluminum tube (6061-T6 A1).

A top view diagram of the lattice arrangement is shown in Figure 15. The Figure shows the neutron detector, pulse neutron source, and external Cf-252 source locations during the experiment.

Fuel elements, two-high in their loading tubes, were loaded into the lattice beginning with the center position and loading outward, filling successive rings of the lattice. At selected fuel loadings for each type of fuel, pulsed neutron source and neutron count rate measurements, respectively, were made to obtain $k_{e f f}$ and a values as the experimental assembly was loaded to a maximum $k_{\text {eff }}$ of 0.97 . 

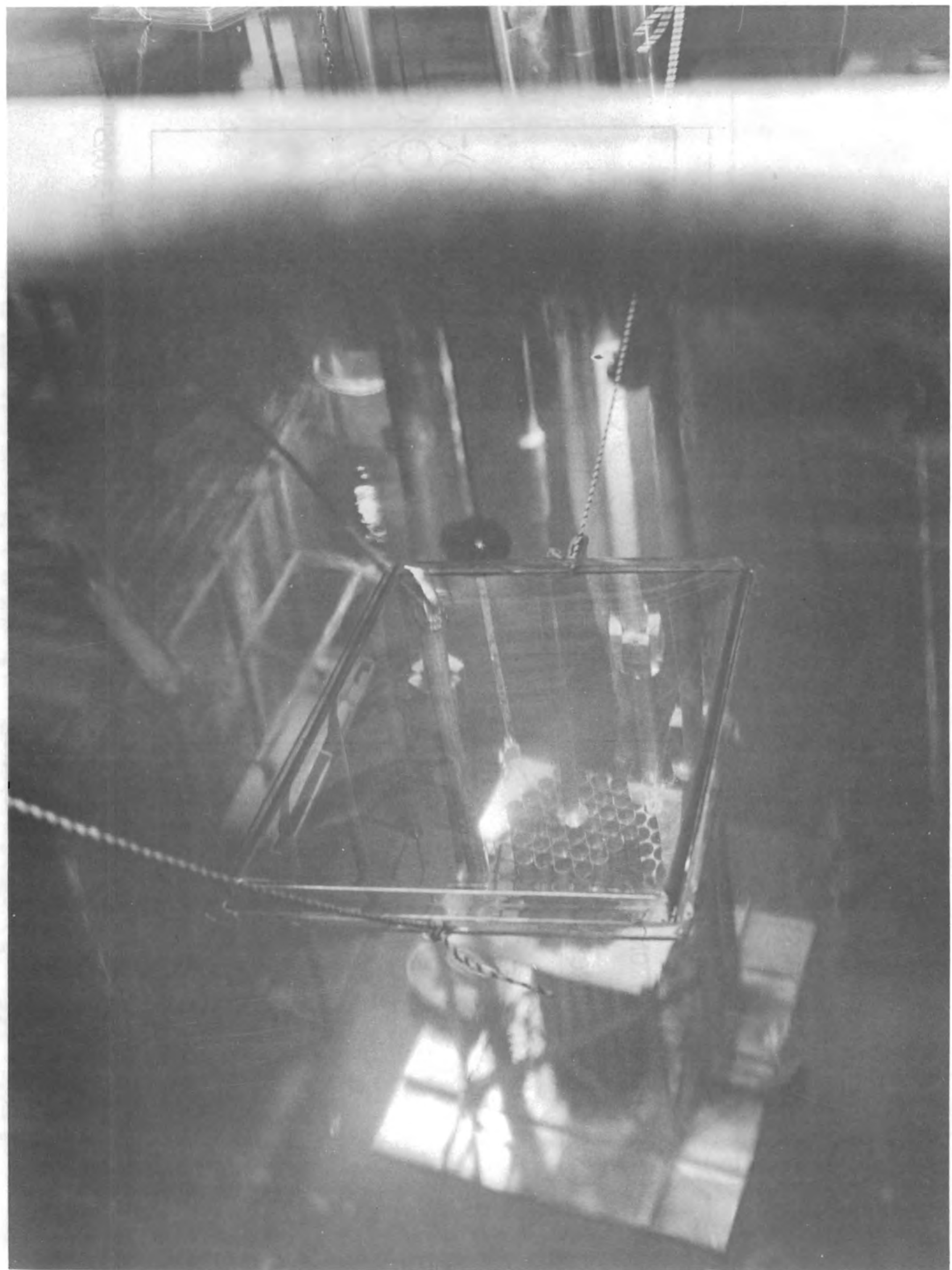

Figure 14. Pulse Neutrorı Measurements Performed on Irradiated Uranium in the $\mathrm{N}$-Reactor Fuel Basin 
(1) DETECTOR LOCATION I (PROPORTIONAL COUNTER AND FISSION CHAMBER)

(2) DETECTOR 2 (FISSION CHAMBER)

(3) DETECTOR LOCATIONS 3,4 AND 5 (FISSION CHAMBER)

(P) PULSE NEUTRON SOURCE

(5) CF-252 SOURCE

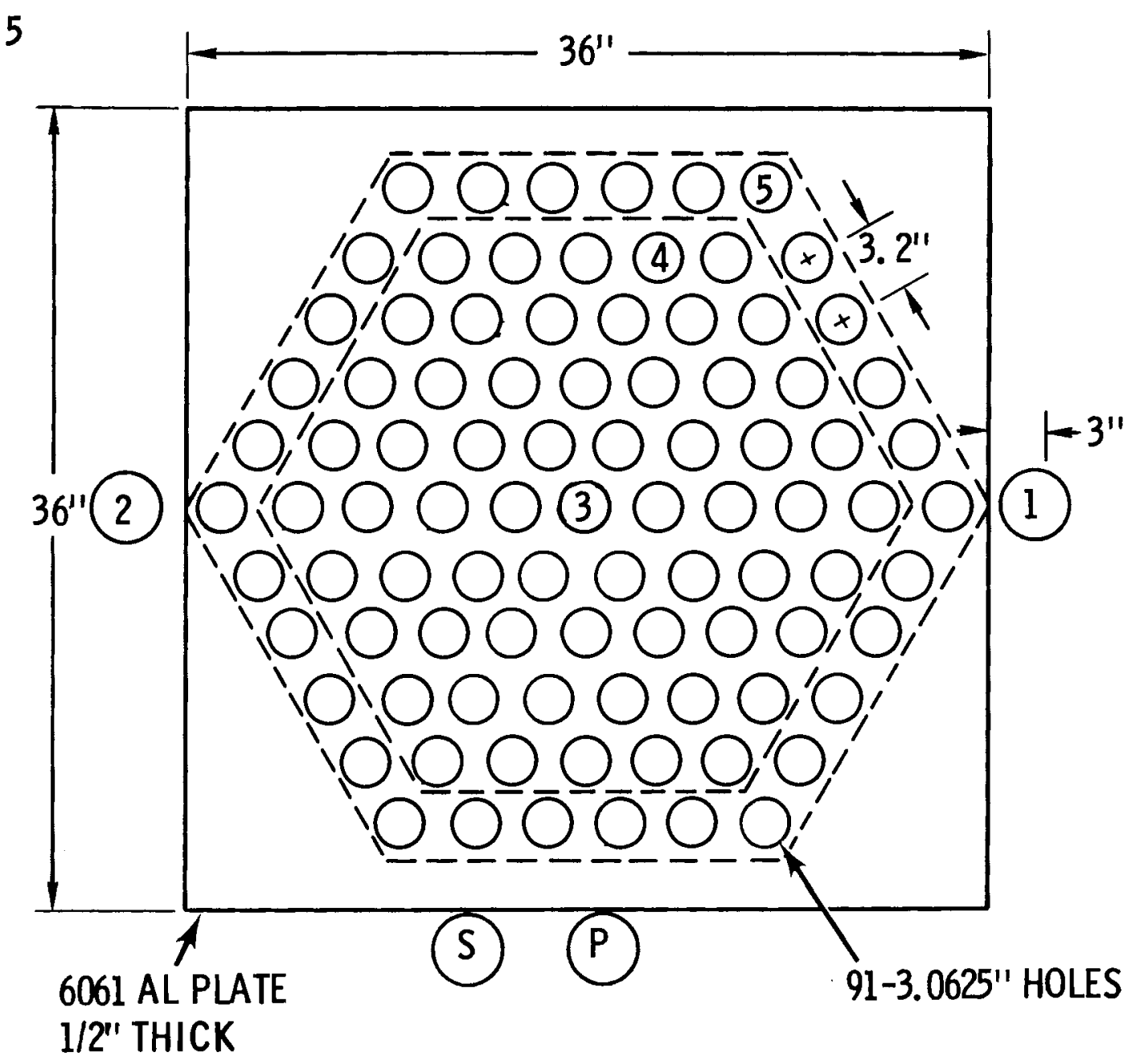

Figure 15. Top View of Experimental Assembly 
The results of the pulsed neutron source measurements on the lattice of unirradiated fuel elements are summarized in Table II. The results for the irradiated fuel elements are summarized in Table III. Values of the prompt neutron decay constant, the term $\mathrm{kB} / \mathrm{l}$, the reactivity as determined by the Garelis-Russell method, and also as determined by the Gozani method, and the average $k_{\text {eff }}$ (with and without spatial effect corrections) are presented in these two tables for each lattice loading at which measurement data were obtained. 


\begin{tabular}{|c|c|c|c|c|c|c|}
\hline \multirow{2}{*}{$\begin{array}{l}\text { Assembly Loading } \\
\text { (Fuel Col umns) } \\
\text { (1) }\end{array}$} & \multirow{2}{*}{$\begin{array}{c}\text { Prompt Neutron } \\
\text { Decay Rate } \\
\left(\mathrm{sec}^{-1}\right) \\
\end{array}$} & \multirow[b]{2}{*}{$\begin{array}{r}k B / \ell \\
\left(\mathrm{sec}^{-1}\right) \\
\end{array}$} & \multicolumn{2}{|c|}{ Reactivity $(2)$} & \multirow[b]{2}{*}{$\begin{array}{l}k_{e f f}(3) \\
\text { (avg) } \\
\end{array}$} & \multirow{2}{*}{$\begin{array}{l}\text { Corrected } \\
k_{\text {eff }}(4) \\
\text { (avg) } \\
\end{array}$} \\
\hline & & & $\begin{array}{l}{ }^{\rho} \mathrm{GR} \\
(\$) \\
\end{array}$ & $\begin{array}{r}{ }^{\circ} \mathrm{GO} \\
(\$) \\
\end{array}$ & & \\
\hline 0 & $4058 \pm 32$ & ----- & $-\ldots$ & $-\ldots$ & ---- & $-\ldots$ \\
\hline 7 & $3954 \pm 40$ & $-\ldots-$ & ----- & ---- & $-\cdots-$ & ---- \\
\hline 19 & $3756 \pm 31$ &.---- & ----- & --- & $--\cdots$ & ---- \\
\hline 37 & $2139 \pm 40$ & 36.27 & -57.98 & -48.00 & 0.74 & ----- \\
\hline 43 & $1824 \pm 14$ & 58.25 & -30.04 & -27.82 & 0.84 & $-\cdots--$ \\
\hline 43 & $1825 \pm 17$ & 56.30 & -31.41 & -29.74 & 0.83 & $-\ldots-$ \\
\hline 49 & $1546 \pm 11$ & 68.43 & -21.60 & -21.38 & 0.88 & ----- \\
\hline $49^{(5)}$ & $1440 \pm 27$ & 65.85 & -20.88 & -20.52 & 0.88 & ---- \\
\hline 51 & $1439 \pm 11$ & 73.56 & -18.56 & -18.93 & 0.89 & 0.92 \\
\hline 54 & $1257 \pm 6$ & 87.09 & -13.43 & -13.92 & 0.92 & 0.95 \\
\hline 54 & $1229 \pm 7$ & 73.45 & -15.29 & -16.22 & 0.91 & 0.94 \\
\hline 78.2 & ---- & ---- & $\ldots-\ldots$ & ---- & ----- & 1.0065 \\
\hline $80.4^{(6)}$ & $---\cdots$ & 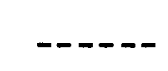 & $-\ldots-$ & ----- & ----- & 1.0065 \\
\hline $54^{(6)}$ & $1414 \pm 15$ & 82.51 & -16.14 & -16.57 & 0.90 & 0.93 \\
\hline${ }_{54}^{(6)(7)}$ & $1442 \pm 9$ & 129.33 & -10.15 & -10.86 & 0.94 & 0.94 \\
\hline $48^{(6)}$ & $1763 \pm 11$ & 57.95 & -29.43 & -29.74 & 0.84 & ------ \\
\hline $42^{(6)}$ & $2052 \pm 29$ & 40.05 & -50.24 & -45.73 & 0.77 & -- \\
\hline $36^{(6)}$ & $2391 \pm 54$ & 22.75 & -104.11 & -84.85 & 0.62 & 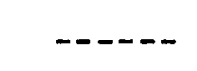 \\
\hline
\end{tabular}

(1) Each fuel column is two fuel elements in length.

(2) Reactivity determined by Garel is-Russell and Gozani methods.

(3) Average of values determined from Garelis-Russell and Gozani methods assuming

(4) $\begin{aligned} & \beta_{\text {eff }}=0.0065 \text {. } \\ & \text { Corrected for kinetic distortion and assuming } \beta_{\text {eff }}=0.0065 \text {. }\end{aligned}$

(5) Data accumulated using Detector 2 (fission chamber) on opposite side of assembly from Detector 1.

(6) Center fuel column placed in outer ring of fuel and Detector 3 placed in center of assembly.

(7) Data accumulated using Detector 3 (fission chamber) in center of assembly. 
EXPERIMENTAL DATA ON 3.2-INCH PITCHED HEXAGONAL

LATTICE OF IRRADIATED MARK-IA FUEL IN WATER

\begin{tabular}{|c|c|c|c|c|c|c|}
\hline \multirow{2}{*}{$\begin{array}{c}\text { Assembly Loading } \\
\text { (Fuel Columns) } \\
\text { (1) }\end{array}$} & \multirow{2}{*}{$\begin{array}{l}\text { Prompt Neutron } \\
\text { Decay Rate } \\
\text { (sec-1) } \\
\end{array}$} & \multirow[b]{2}{*}{$\begin{array}{c}\mathrm{kB} / \mathrm{l} \\
\left(\mathrm{sec}^{-1}\right)\end{array}$} & \multicolumn{2}{|c|}{ Reactivity ${ }^{(2)}$} & \multirow[b]{2}{*}{$\begin{array}{l}k_{\text {eff }}(3) \\
\text { (avg) } \\
\end{array}$} & \multirow{2}{*}{$\begin{array}{c}\text { Corrected } \\
\mathrm{k}_{\text {eff }}(4) \\
\text { (avg) } \\
\end{array}$} \\
\hline & & & $\begin{array}{l}\rho_{G R} \\
(\$)\end{array}$ & $\begin{array}{l}{ }^{\rho}{ }_{G 0} \\
(\$)\end{array}$ & & \\
\hline 67 & $1676 \pm 89$ & 24.10 & -68.56 & -70.94 & 0.72 & 0.76 \\
\hline 73 & $1574 \pm 24$ & 68.82 & -21.87 & -24.51 & 0.88 & 0.91 \\
\hline 79 & $1495 \pm 42$ & 79.33 & -17.84 & -22.49 & 0.90 & 0.92 \\
\hline 85 & $1342 \pm 25$ & 93.44 & -13.37 & -15.92 & 0.92 & 0.94 \\
\hline 91 & $1261 \pm 21$ & 108.02 & -10.67 & -12.59 & 0.94 & 0.96 \\
\hline 158.5 & ------ & ------ & ------ & ----- & ------ & 1.0056 \\
\hline $150.9^{(5)}$ & ----- & ----- & -..-- & $--\cdots$ & $-\cdots--$ & 1.0056 \\
\hline $90^{(5)}$ & $1356 \pm 33$ & 99.62 & -12.61 & -14.44 & 0.93 & 0.95 \\
\hline $90^{(5)(6)}$ & $1361 \pm 6$ & 131.59 & -9.34 & -10.35 & 0.95 & 0.95 \\
\hline $78^{(5)}$ & $1626 \pm 30$ & 96.52 & -15.80 & -19.60 & 0.91 & 0.93 \\
\hline $78^{(5)(6)}$ & $1634 \pm 13$ & 120.94 & -12.51 & -14.33 & 0.93 & 0.93 \\
\hline $60^{(5)}$ & $2047 \pm 80$ & 54.41 & -36.63 & -43.48 & 0.82 & 0.90 \\
\hline $54^{(5)(6)}$ & $2285 \pm 21$ & 102.78 & -21.23 & -25.47 & 0.88 & 0.88 \\
\hline
\end{tabular}

(1) Each fuel column is two fuel elements in length.

(2) Reactivity determined by Garel is-Russell and Gozani methods.

(3) Average of values determined from Garelis-Russell and Gozani methods assuming $\beta_{\text {eff }}=0.0056$.

(4) Corrected for kinetic distortion and assuming $\beta_{\text {eff }}=0.0056$.

(5) Center fuel column placed in outer ring of fuel and Detector 3 placed in center of assembly.

(6) Data accumulated using Detector 3 (fission chamber) in center of assembly. 
Values for the effective delayed neutron fractions of the unirradiated and the irradiated fuel were taken to be 0.0065 and 0.0056 . These were given by $H$. Toffer of the il-Reactor Technical Division.

The $k_{\text {eff }}$ values given in Tables II and II have been corrected to account for the spatial dependency present in the reactivity analyses due to the detector being in a region (Location 1) where the prompt and delayed fission distributions are not the same. By assuming the prompt and delayed fission distributions are essentially the same over the center region of each lattice, measured correction factors can be obtained by accumulating measurement data with a detector in the center of the lattice. Therefore, during the unloading of each lattice, pulsed neutron source measurements were made on selected loadings not only with a detector at Location Number 1 , but also with a detector in the center of the lattice (Location 3) to obtain the experimental spatial correction factors for Detector Location 1.

Extrapolation of the pulsed neutron $k_{\text {eff }}$ data indicate delayed critical loadings of about 73 and 140 fuel columns for the unirradiated and irradiated fuel, respectively.

In summarizing, pulse neutron source measurements were performed on spent and "green" fuel in the $\mathrm{N}$-Reactor fuel storage basin. The values of $k_{\text {eff }}$ measured ranged from about 0.6 to 0.96 and a sizeable difference in critical mass was observed in comparing green and spent fuel. 


\section{FUTURE APPLICATIONS}

The pulsed neutron source method has been used in a variety of circumstances to measure reactivities of subcritical arrays of fuel rods in water. The method has largely been used to generate experiment data that can be compared with calculational data, whether in verifying a computer-calculated system reactivity or measuring a system response to changes in critical parameters. The system was designed for remote use in the field and is extremely flexible.

However, there are areas where it's flexibility and applicability might be improved. Presently, count rate data is output to paper tape. This in turn is then transferred to cards and subsequently input into a computer code at a main terminal. One obvious improvement in this method would be to integrate a mini computer into the system and make data reduction one of the on-line steps in the measuring process. Results would then be readily available at the point of measurement.

In addition, with the advent of newer multichannel analyzer systems, data can now be collected simultaneously at more than a single detector location. Hence, spatial effects can be accurately and more quickly analayzed. 
These features coupled together suggest the pulsed neutron source technique could then be used to analyze reactivities of much larger systems, where a series of measurements would be required, for example fuel storage basins. Experimental results presented in this report show that subcritical system reactivities in the range of 0.6 to 1.0 can be measured for fuel rod systems in water whether the fuel is irradiated or unirradiated. In addition, reactivities for clustered systems have been measured. Since a fuel storage basin is a large array of clusters of fuel rods, a similar measurement technique should be successful, assuming that $k_{\text {eff }}>0.6$. The only significant difference is in system size. The large array can be viewed as a composite of a number of smaller, weakly interacting arrays. The technique would be then to divide the basin reasurement into a large grid of smaller array measurements. Since each measurement is a measure of a localized fuel region reactivity, the maximum fuel basin reactivity is the reactivity of the largest component.

Another improvement would be to incorporate the measuring equipment into a small van. This not only would insure safer handling of electronics equipment, but the equipment would be easily transportable to plant locations for in-situ measurements in the field.

Taken together, these changes would make the present system more flexible and adaptable to a wider variety of reactivity measuring problems. Data would be analyzed more quickly, bringing to the surface potential problems at the time of measurement. 


\section{CONCLUSIONS}

The purpose in writing this document was to demonstrate how the pulse neutron technique has been used at Pacific Northwest Laboratory in the past for measurements of subcritical reactivities of fuel rods in water and to suggest how it might be used in the future.

A wide variety of applications have been described and some future applications have been mentioned. Like any method of measurement, there are inherent strengths and weaknesses. The pulsed neutron source technique is most accurate near delayed critical, becoming less accurate further from critical. However, it has been demonstrated that utilizing the Garelis-Russell and Gozani techniques, the "true" keff can be bracketed. With this tool in hand, it has been shown herein that $k_{\text {eff }}$ measurements have been made in the far subcritical region with some degree of confidence.

Some changes have been suggested to expand the present system capability and improve the data analysis process. Such changes will not only improve the system use for the present kinds of small process vessel problems but make the system more applicable to measurements on larger systems such as fuel storage basin arrays. It is felt that this technique can be utilized on larger arrays, thus providing a useful tool for assessing the criticality safety of systems such as fuel elements in storage pools. 


\section{REFERENCES}

1. N. G. Sjöstrand, "Measurement on a Subcritical Reactor Using a Pulsed Neutron Source," Arkiv Fysik, 11, 233 (1956)

2. T. Gozani, "A Modified Procedure for the Evaluation of Pulsed Source Experiments in Subcritical Reactors," Nukleonik, 4 , 348 (1962)

3. E. Garel is and J. L. Russe11, "Theory of Pulsed Neutron Source Measurements," Nuclear Science and Engineering, 16, 263 (1963)

4. B. H. Duane, "Maximum Likel ihood Nonlinear Correlated Fields (BNW Program LIKELY)," BNWL-390, September 1967

5. G. D. Seybold, User's Aid: "Programs LEARN and LIKELY," BNWL-1057, May 1969

6. T. Gozani, P. DeMarmels, T. Hurlimann and H. Winkler, "On the Modified Pulsed Source Techniques," IAEA, Karlsruhe Symposium on Pulsed Neutron Research (1965)

7. R. C. Lloyd, et al., "Criticality Studies of a Neutron Multiplier Lattice," Nuclear Technology, 37, 148 (1978)

8. J. T. Long, "Revision 1, Safety Review - Shipping PuAl Elements in the Paducah Demonstration Cask," DUN-7834 REV 1, March 21, 1972

9. H. Toffer, "Criticality Safety Analysis Report - Subcritical Measurements in the Hanford N-Reactor Storage Basin," DUN-7824, ADD. 1, February 27, 1975 


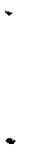




\section{DISTRIBUTION}

No. of Copies

OFFSITE

1

1
DOE Chicago Patent Group

Energy Research and Development Administration

Chicago Operations office

9800 South Cass Avenue

Argonne, IL 60439

A. A. Churm

DOE Technical Information Center

Nuclear Regulatory Commission

Washington, DC 20555
Norman Ketzlach
Charles Marotta
R. H. Odegaarden
Russell Stanford

E. I. du Pont de flemours and Co. Savannah River Laboratory

Aiken, SC 20801
H. K. Clark

Union Carbide Corporation (ORNL)

Oak Ridge National Laboratory

P. 0. Box $X$

Oak Ridge, TN 37830

G. E. Whitesides

J. F. Mincey

University of California (LLL)

Lawrence Livermore Laboratory

P. 0. Box 808

Livermore, CA 94550

Brian Koponen 
No. of

Copies

ONSITE

DOE Richland Operations Office, Programs Division

H. E. Ransom

Rockwe11 Hanford Operations

1

R. D. Carter

Hanford Engineering Development Laboratory

$\because 1$

C. A. Rogers

Pacific Northwest Laboratory

5

1

1

1

5

1
S. R. Bierman

C. L. Brown

E. D. Clayton

L. R. Dodd

B. M. Durst

B. F. Gore

U. P. Jenquin

R. A. Libby

R. C. Lloyd

W. L. Purcell

Technical Information Files

Publishing Coordination 


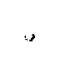

.

. 